\title{
No additional effect to infant birthweight if both parents are obese to that of one: retrospective analysis of 1479 singleton term births following assisted reproductive treatment
}

\author{
Nicole McPherson ${ }^{1}$, Andrew Vincent ${ }^{1}$, Deirdre Zander-Fox ${ }^{2}$, and Jessica Grieger ${ }^{1}$ \\ ${ }^{1}$ The University of Adelaide \\ ${ }^{2}$ Monash IVF Group
}

May 29, 2020

\begin{abstract}
Objective: To determine the combined effects of maternal and paternal preconception overweight and obesity on infant birthweight. Design: Retrospective data analysis, fresh cycles (2009-2017), Repromed, South Australia. Setting: Assisted Reproductive Technology. Population: Couples undergoing either in vitro fertilisation or intracytoplasmic sperm injection with their own gametes and transfer of a single blastocyst $(\mathrm{N}=1479)$. Methods: Maternal and paternal BMI were recorded prior to cycle initiation. Infant birthweight was recorded at delivery. The impact of paternal and maternal overweight and obesity and their interaction on infant birthweight was assessed using quantile regressions constructed at 5th, 10th, 50th, 90th and 95th birthweight percentiles based on Australian standards. Main Outcome Measures: First, singleton, term birth ([?] 37 weeks' gestation) birthweight. Results: There was weak evidence for an interaction between parental BMI for median birth weight $(\beta=-0.98 ; 95 \% \mathrm{CI}=[-1.90,-0.05], \mathrm{p}=0.04)$ with infants having increasing birth weight with increasing parental BMI, when one parent has normal weight. When either parent is overweight or obese, although birth weights are higher (maternal $\beta=15.9$; $95 \% \mathrm{CI}=[1.63,30.1], \mathrm{p}=0.03$; paternal $\beta=7.33 ; 95 \% \mathrm{CI}=[0.297,14.4] \mathrm{p}=0.04)$, they are not associated with increasing BMI of the other parent. Conclusions: Both maternal and paternal overweight and obesity at conception independently increase median infant birthweight. These findings necessitate the need for a family centered approach for preconception counselling on healthy BMI prior to pregnancy. Further studies are warranted in other ART or general population cohorts to support or refute our findings. Funding: NOM is the recipient of an NHMRC Early Career Fellowship.
\end{abstract}

\section{INTRODUCTION}

Obesity is a significant public health concern. There is a rising trend for increased body mass index (BMI) across all age groups with obesity rates tripling over the past 40 years ${ }^{1}$. The World Health Organization (WHO) reported that $39 \%$ of adults aged 18 years and over were overweight in 2016 , and $13 \%$ were obese with obesity being a major risk factor for non-communicable diseases including type 2 diabetes and cardiovascular diseases ${ }^{2}$. A global systematic analysis found that women of reproductive age demonstrate a particularly steep increase in obesity prevalence ${ }^{3}$, with 38.9 million pregnant women estimated to be overweight and 14.6 million estimated to be obese, in $2014^{4}$. In Australia, nearly half of women who gave birth were overweight or obese in $2017^{5}$. A similar trend in overweight and obesity prevalence has also been seen in men of reproductive age ${ }^{3}$.

There is consistent evidence that maternal preconception BMI affects infant birthweight, such that maternal overweight or obesity increases the likelihood for an infant being born large for gestational age (LGA) $(\mathrm{OR}=1.45 ; 95 \% \mathrm{CI}=[1.29,1.63]$ and $\mathrm{OR}=1.88 ; 95 \% \mathrm{CI}=[1.67,2.11]$, respectively $)$ or macrosomic $(\mathrm{OR}=1.70$; $95 \% \mathrm{CI}=[1.55,1.87]$ and $\mathrm{OR}=2.92 ; 95 \% \mathrm{CI}=[2.67,3.20]$, respectively) ${ }^{6}$. In comparison the risk of delivering a small for gestational age (SGA) baby are increased in underweight mothers $(\mathrm{OR}=1.67 ; 95 \% \mathrm{CI}=$ 
[1.49-1.87]); but decreased with overweight $(\mathrm{OR}=0.71 ; 95 \% \mathrm{CI}=[0.66,0.76])$ or obese mothers $(\mathrm{OR}=0.88$; $95 \% \mathrm{CI}=[0.78,0.99])^{6}$. Increased maternal BMI also influences child overweight and obesity risks up to 14 years of age ${ }^{7}$ and increases future risk for obesity and cardio-metabolic diseases later life for both mother and child $^{8}$. Problematically, the potential impact of paternal BMI is rarely considered in these studies, despite a small body of evidence suggesting that paternal preconception overweight and obesity may also contribute to infant birthweight including the delivery of an SGA or LGA infant ${ }^{9,}{ }^{10}$. Thus the involvement of paternal overweight and obesity on infant birthweight demonstrates a role for the father's preconception health in programing fetal outcomes ${ }^{11}$.

It is evident that maternal preconception BMI affects infant birthweight, however the influence of paternal preconception BMI is less studied. Further it is unclear whether there is an additional effect on infant birthweight if both parents are overweight or obese. We hypothesise that the combination of both maternal and paternal preconception overweight/obesity has a larger contribution to infant birthweight than their independent parental effects. The objective of this study is to assess the independent and combined effects of maternal and paternal preconception overweight and obesity on infant birthweight utilising an assisted reproductive technologies (ART) cohort where preconception parental BMI is routinely collected.

\section{METHODS}

\section{Study population and data collection}

Retrospective data analysis of fresh cycles from 2009-2017 at Repromed (Dulwich, South Australia and Darwin, Northern Territory clinics). Cycles including either in vitro fertilisation (IVF) or intracytoplasmic sperm injection (ICSI) with autologous sperm and eggs and the transfer of a single blastocyst embryo were assessed (Figure S1). First singleton term birth ([?] 37 weeks' gestation) with a birth weight recorded were included in the analysis. Pre-term ( $<37$ weeks' gestation), twin births and second pregnancies from the same patient couple were excluded from the analysis (Figure S1). Parental data was collected from case notes including demographic data (socioeconomic index for areas (SEIFA), ART information (insemination method and infertility diagnosis) and maternal and paternal age. SEIFA was calculated by patient's postcode ${ }^{12}$. A high score indicates greater social advantage, while a low score indicates relatively greater disadvantage; the average SEIFA score is 1000 and the middle two-thirds of SEIFA scores will generally fall between $\sim 900$ and $1100^{12}$.

Birth outcomes including infant birthweight (g), gestational age (weeks), sex (male/female), twin deliveries, and delivery method (vaginal/caesarean), were supplied by the treating obstetrician as per the ART treatment act that indicates mandatory reporting to the Australian and New Zealand Assisted Reproduction Database (ANZARD). Small for gestational age (SGA) infants were classified as [?]10 ${ }^{\text {th }}$ percentile, while large for gestational age (LGA) infants were classified as [?] $90^{\text {th }}$ percentile, based on Australian specific birthweight standards reported in Dobbinset al. ${ }^{13}$.

\section{Human ethics}

Repromed's Scientific Advisory Board (SAC) approved the retrospective study (14/11/2019); the study was exempt from HREC review at the University of Adelaide. Formal consent for this type of study is not required.

\section{Assessment of parental BMI}

As part of clinical practice at Repromed, BMI is routinely recorded before cycle initiation. Both maternal and paternal height is measured with a stadiometer $(\mathrm{cm})$ and weight $(\mathrm{kg})$ measured with electronic scales, assessed by a clinical nurse prior to cycle commencement. Body mass index was calculated using the formula weight $/$ height ${ }^{2}$ and categorized based on the WHO; underweight $\left(<18.5 \mathrm{~kg} / \mathrm{m}^{2}\right)$; normal weight $(18.5-24.9$ $\left.\mathrm{kg} / \mathrm{m}^{2}\right)$; overweight $\left(25.0-29.9 \mathrm{~kg} / \mathrm{m}^{2}\right)$; obesity $\left(>30.0 \mathrm{~kg} / \mathrm{m}^{2}\right)$, with obesity class I, $30.0-34.9 \mathrm{~kg} / \mathrm{m}^{2}$, obesity class II, $35.0-39.9 \mathrm{~kg} / \mathrm{m}^{2}$, and obesity class III, $>40 \mathrm{~kg} / \mathrm{m}^{2}$.

\section{IVF protocol}


Women primarily underwent a GnRH antagonist protocol of treatment with vaginal progesterone gel (Crinone) / estradiol valterate luteal support or human-derived hCG luteal support (pregnyl) as previously described $^{14}$. At the time of study (2009-2017) there were minimal changes to laboratory protocols including culture media, consumables or equipment used. Eggs were fertilised by either standard IVF or ICSI in fertilization medium (G-IVF-PLUS, Vitrolife, Gothenberg, Sweden). Embryos were cultured using the sequential culture media system supplied by Vitrolife at $6 \% \mathrm{CO}_{2}, 5 \% \mathrm{O}_{2}$ and $89 \% \mathrm{~N}_{2}$ where cleavage-stage embryos were grown until day 3 in G1 PLUS and then moved into G2 PLUS which supports blastocyst development until embryo transfer on day 4 or day 5 . The best morphological graded embryo was transferred back into the patient using EmbryoGlue transfer medium (Vitrolife). Patients were in the care of their treating IVF physician until confirmation of a viable pregnancy following ultrasound at 6-8 weeks' gestation, where they were then referred onto primary obstetrics care.

\section{Statistical Methods}

For continuous demographic, treatment and outcome factors, means (standard deviations (SDs)) and medians (ranges) are reported, and for discrete factors, frequencies (percentages) are reported. The impact of paternal and maternal BMI on infant birthweight was assessed using quantile regressions, adjusting for baby sex (male or female), gestational age, delivery method (vaginal or caesarean), transfer method (IVF or ICSI), maternal age, paternal age and parental SEIFA score. Non-linear associations using restricted cubic splines (knots at $5^{\text {th }}, 10^{\text {th }} 50^{\text {th }}, 90^{\text {th }}$ and $95^{\text {th }}$ percentiles) were included for gestational age and maternal BMI. An interaction between the maternal and paternal BMI factors (both linear) was also included. These quantile regressions were constructed for the $5^{\text {th }}, 10^{\text {th }}, 50^{\text {th }}, 90^{\text {th }}$ and $95^{\text {th }}$ weight percentiles based on Australian specific birthweight standards ${ }^{13}$ (Figure S2). Multiple imputation using chained equations (100 datasets were imputed each with 100 iterations) was employed to account for the substantial missing paternal BMI data. Analyses were performed in $\mathrm{R}$ (version 3.6.3) using the mice and rms packages. P-values of 0.05 were considered statistically significant.

\section{RESULTS}

Patient demographics

A total of 1479 couples were included in the analysis (Figure 1). The median age of mothers was 32.9 years $($ range $=[19.9,45.2])$, which was lower than the median age of fathers (35.2 years; range $=[20.5,65.4])($ Table 1 ). The median BMI of mothers $\left(24.4 \mathrm{~kg} / \mathrm{m}^{2}\right.$; range $\left.=[16.2,55.9]\right)$, was in the normal weight category, although BMI spanned both underweight $\left(<18.5 \mathrm{~kg} / \mathrm{m}^{2}\right)$ through obese class III $\left(>40 \mathrm{~kg} / \mathrm{m}^{2}\right)$ categories. The median BMI of fathers $\left(27.4 \mathrm{~kg} / \mathrm{m}^{2}\right.$; range $\left.=[17.3,54.2]\right)$, was in the overweight category, and similar to mothers, spanned from underweight to obese class III (Table 1). The mean (SD) SEIFA score was 994 (72), indicating a slightly lower score than the Australian benchmark of 1000, indicating social disadvantage. Male factor infertility was the biggest contributing infertility diagnosis $(55 \%)$ to the cohort (Table 1). ICSI insemination was used in over $80 \%$ of cases with delivery method (vaginal vs caesarean) and infant sex (female vs male) split approximately $50 \%$ (Table 1 ).

Other risk factors and infant birthweight

Table 2 and Table 3 presents the three quantile regression models for SGA and LGA infants, and Figure S3 presents model estimates for continuous covariates. Infants born to older mothers were more likely to be SGA $\left(10^{\text {th }}\right.$ percentile: $\left.\beta=-15.2,95 \% \mathrm{CI}=[-23.0,-7.34], \mathrm{p}=0.001\right)$, but not LGA $(\mathrm{p}=0.59)$ and had a reduced median birthweight $\left(50^{\text {th }}\right.$ percentile: $\left.\beta=-7.5,95 \% \mathrm{CI}=[-14.9,-0.05], \mathrm{p}=0.05\right)$. While older fathers had a reduced risk of fathering an SGA infant $\left(10^{\text {th }}\right.$ percentile: $\left.\beta=9.5,95 \% \mathrm{CI}=[4.15,14.8], \mathrm{p}=0.0005\right)$. Higher SEIFA scores were associated with increased median infant birthweight $(\beta=44.3,95 \% \mathrm{CI}=[16.7,71.8], \mathrm{p}=0.002)$ and a reduced risk of an SGA infant $(\beta=32.0,95 \% \mathrm{CI}=[7.92,56.1], \mathrm{p}=0.009$.

Male infants had higher birthweight compared with females by a similar amount in all regression analysis (all p[?]0.03). Birthweight increased non-linearly with gestational age with smaller increases in weight for gestational ages $>40$ weeks. This tapering in the increase in birth weight was more extreme for SGA 
( $10^{\text {th }}$ percentile: $\mathrm{p}=0.003$ and $5^{\text {th }}$ percentile: $\left.\mathrm{p}=0.004\right)$ than for LGA $\left(90^{\text {th }}\right.$ percentile: $\mathrm{p}=0.16$ and $95^{\text {th }}$ percentile: $\mathrm{p}=0.03)$. Infants delivered by caesarean section were more likely to be heavier $\left(90^{\text {th }}\right.$ percentile: $\beta=133,95 \% \mathrm{CI}=[62.3,203], \mathrm{p}<0.0002)$, however their risk for SGA was not different to babies delivered vaginally $(\mathrm{p}=0.82)$. There was no detectable influence of insemination method on infant birthweight.

Parental preconception BMI and infant birthweight

Figure 1 presents model estimates for parental BMI associations with infant birthweight. There was weak evidence for an interaction between parental BMIs for median birth weight $(\beta=-0.98 ; 95 \% \mathrm{CI}=[-1.90,-0.05]$, $\mathrm{p}=0.04$ ) with infants having increasing birth weight with increasing parental BMI, when one parent has normal weight (Figures 1A and $1 \mathrm{C}$ ). When either parent was overweight or obese, although median infant birthweight are higher (maternal $\beta=15.9 ; 95 \% \mathrm{CI}=[1.63,30.1], \mathrm{p}=0.03$ and paternal $\beta=7.33 ; 95 \% \mathrm{CI}=[0.297$, 14.4] $\mathrm{p}=0.04$ ), they were not associated with increasing BMI of the other parent (Figure 1B and Figure 1D).

Maternal overweight and obesity was associated with increased risk of extreme LGA (95 ${ }^{\text {th }}$ percentile: $\beta=-$ 25.1; $95 \% \mathrm{CI}=[5.07,45.1], \mathrm{p}=0.01)$, while there was no effect of increasing paternal BMI $\left(90^{\text {th }}\right.$ percentile: $\mathrm{p}=0.50 ; 95^{\text {th }}$ percentile: $\left.\mathrm{p}=0.43\right)$. In both the median, $90^{\text {th }}$ and $95^{\text {th }}$ percentile models, there was no evidence of a non-linear association between maternal BMI and birthweight (median: $p=0.61 ; 90^{\text {th }}$ percentile: $\mathrm{p}=0.32 ; 95^{\text {th }}$ percentile: $\mathrm{p}=0.70$ ). However, in the $5^{\text {th }}$ and $10^{\text {th }}$ percentile regression there was a strong nonlinear association between maternal BMI and infant birthweight $(p=0.002$ and $p=0.03)$. Such that infant birthweight increased with maternal BMI, approximately $27.5 \mathrm{~kg} / \mathrm{m}^{2}$ or lower, but for maternal BMIs in the obese range $\left(>30 \mathrm{~kg} / \mathrm{m}^{2}\right)$, the $5^{\text {th }}$ percentile of infant birthweight plateaued, indicating a greater divergence from the median baby weights and greater risks of SGA. There was no effect of paternal BMI and risk of SGA infants $\left(5^{\text {th }}\right.$ percentile: $\mathrm{p}=0.60 ; 10^{\text {th }}$ percentile: $\left.\mathrm{p}=0.52\right)$.

\section{DISCUSSION}

Main Finding

In a retrospective cohort study of 1479 singleton births following ART, we demonstrate no additional impact on infant birthweight when both parents were overweight or obese compared to just one parent alone. That is, while infants born to overweight and obese mothers or fathers were heavier, the joint effect is not additive.

\section{Strengths and Limitations}

To our knowledge, this is the first study assessing the combined contribution of maternal and paternal preconception overweight and obesity on infant birthweight. The strengths of our study include the use of a database in which preconception health, IVF cycle outcomes and pregnancy rates were registered prospectively, thereby minimising selection bias; BMI was calculated from clinically recorded measurements of maternal and paternal preconception weights and heights; the analysis only included first singleton term births; and the large population size from a singular ART unit limited variability in clinical protocols. Limitations of our study include the retrospective study design, which limits the degree of causal inference; reduced ability to control for some key parental factors that can influence infant birthweight, including parental smoking ${ }^{15,16}$ and maternal gestational weight gain ${ }^{17}$ and further, the fact that the utilization of an ART cohort is confounded by subfertility andin vitro embryo culture. However, infertility diagnosis has been previously shown to not influence infant birthweight in term pregnancies ${ }^{18,19}$, thus the subfertility diagnosis is unlikely to be contributing to the reported outcomes.

\section{Interpretation}

Contrary to our hypothesis, we found no additional effect of having two overweight or obese parents on infant birthweight outside what was seen if one parent was overweight or obese. Evidence from our rodent model of obesity also suggests that the effect on infant birthweight may unlikely be additive, but an accumulation of both the negative maternal and paternal phenotypes ${ }^{20}$. This seems to be evident in our human cohort where infant birthweight increased from $3.13 \mathrm{~kg} 95 \% \mathrm{CI}=[3.03,3.23]$ to $3.44 \mathrm{~kg} 95 \% \mathrm{CI}=[3.31,3.56]$ in normal weight mothers compared with obese mothers when fathers were of a normal weight. When fathers were 
obese, this increase was much smaller $(3.33 \mathrm{~kg} 95 \% \mathrm{CI}=[3.20,3.45]$ to $3.41 \mathrm{~kg}[3.32,3.51])$. This is likely because infants born to fathers who are obese already start out heavier $\left({ }^{\sim} 200 \mathrm{~g}\right)$ and therefore, only require a small additional increase in size to match the effect of obese mothers. Whilst we saw no additive effect of combined parental BMI on infant birthweight, the effects maybe may be present as the infants grow. For instance, in another rodent model, insulin resistance and liver steatosis were greatest in offspring when both parents were fed a high fat diet prior to and during gestation, compared to just one parent ${ }^{21}$. In humans, Rath et al. ${ }^{22}$, found that parental obesity was the strongest predictor of offspring adult BMI. These data suggest that the combined effect of having two obese parents on infant programming may manifest later in life.

There is a large body of literature demonstrating the impact of maternal BMI on infant birthweight including LGA ${ }^{23}$, and there is some suggestion for paternal BMI also having an impact on infant birthweight ${ }^{9}$. Unfortunately, much of the literature on paternal BMI included self-reported paternal height and weight from the mother, or, collection during pregnancy, at birth, or when the child was a toddler, rather than preconception ${ }^{24,25}$. Furthermore, studies that have assessed preconception paternal BMI have not always adequately controlled for maternal and other parental cofactors, and therefore, the results are currently conflicting. For example Chen et al., ${ }^{26}$ found that paternal overweight and obesity only influence male infant birthweight, with a 1 unit increase in paternal BMI associated with a $19.5 \mathrm{~g}$ increase in infant birthweight, while Noor et al . ${ }^{27}$ found that fathers with a BMI greater than $25 \mathrm{~kg} / \mathrm{m}^{2}$ increased infant birthweight in both sexes (z score, 0.38 [0.91] vs 0.11 [0.96]. In contrast, three other studies found no effect of paternal $\mathrm{BMI}$ on infant birthweight ${ }^{28-30}$. Interestingly, when assessing the extreme ends of infant birthweight (SGA or LGA), McCownet al., ${ }^{31}$ found that obese men were 1.5 times more likely to father SGA infants, while Yang et al. ${ }^{32}$ found that overweight and obese men were 1.3 times and 1.9 times respectively more likely, to father an LGA infant. Similarly, in an ART cohort following frozen embryo transfer Ma et al., ${ }^{19}$ found that men who were overweight or obese had an increased odds of having a LGA infant $(\mathrm{OR}=1.43 ; 95 \% \mathrm{CI}=[1.27$, $1.63]$ and $\mathrm{OR}=1.36 ; 95 \% \mathrm{CI}=[1.04,1.79]$ respectively). In our study, we found no evidence for an association between paternal overweight and obesity and SGA or LGA infants $\left(<10^{\text {th }}\right.$ and $>90^{\text {th }}$ percentiles), although the median birthweight of infants were higher with increased paternal BMI ( $7.3 \mathrm{~g}$ for every 1 unit increase in paternal BMI). The lack of consensus in the reported effects of paternal overweight and obesity on infant birthweight highlights the necessity for further adequately controlled cohort studies. Nevertheless, animal models of male obesity support findings for increased infant birthweight ${ }^{33-35}$.

The mechanism for transmission of altered infant birthweight from increasing paternal BMI is likely due to a combination of genetic and epigenetic factors delivered by sperm to the egg at fertilisation ${ }^{36,37}$. A number of genes are known to play a part in the heritability of weight ${ }^{38,} 39$, however these genetic loci do not fully account for the transmission. A number of studies in animal models and humans directly show a link between paternal obesity at conception, sperm epigenetic changes (non-coding RNAs and DNA and histone methylation) and altered fetal phenotypes ${ }^{27}, 40-44$, indicating that the paternal effect goes beyond that of a shared living environment, with preconception factors able to influence the health of subsequent offspring.

Our data shows that infants born from mothers or fathers of increasing BMI start their growth trajectory heavier than those infants born to normal weight mothers or fathers. This is of concern as birthweight has been reported to play an important role in the establishment of adolescent and early adulthood BMI ${ }^{22,45}$. For instance, evidence from the Early Childhood Longitudinal Study in the USA, found that LGA infants made up $1 / 3(36 \%)$ of all children who were obese by age 14 years ${ }^{45}$ and data from the RAINE cohort in Western Australia, Australia, found that both maternal and paternal preconception BMI were strong predictors of childhood, adolescent and adulthood obesity ${ }^{22}$. If obesity aggregates within families, then a focus on preconception planning for family units is recommended. In Australia, there are no primary male preconception health-care initiatives ${ }^{46}$. While Healthy Male (Andrology Australia) does provide education on the reproductive health of men, focusing on fertility, sexuality and fathering, and the Australian men's health policy addresses various issues related to sexual problems, neither of these primarily focus on preconception health ${ }^{46}$. Further, missing data for paternal preconception BMI in our study was nearly double 
that of missing maternal BMI (33\% vs 18\%). While some of this may be due to the lack of males in preconception care appointments, it highlights the dogma that mother's preconception health is a key focus rather than fathers. Therefore, it is recommended that preconception health messages focus on 'healthy couples', emphasising the need to improve lifestyle for the family unit prior to pregnancy.

Conclusion

In conclusion, utilising close to 1500 singleton term births from an ART cohort, our results demonstrate that maternal or paternal overweight and obesity increases infant birthweight independent to the BMI of the other partner, with no additive effects seen if both parents were overweight or obese. Further studies are warranted in both ART and general population cohorts to support or refute our findings. Our results highlight the notion for family unit preconception health initiatives.

\section{DISCLOSURE OF INTERESTS}

NOM and DZ are paid employees of Monash IVF Group Ltd. The remaining authors have no disclosures.

\section{CONTRIBUTIONS TO AUTHORSHIP}

NOM conception, acquisition, interpretation of data, drafting, revising and final approval of the manuscript. $\mathrm{AV}$ conception, analysis, interpretation of data, revising and final approval of the manuscript. DZ conception, revising and final approval of the manuscript. JAG conception, interpretation of data, drafting, revising and final approval of the manuscript.

\section{FUNDING}

NOM is the recipient of an NHMRC Early Career Fellowship.

\section{ETHICS APPROVAL}

Repromed's Scientific Advisory Board (SAC) approved the retrospective study (14/11/2019); the study was exempt from HREC review at the University of Adelaide. Formal consent for this type of study is not required.

\section{REFERENCES}

1. National Academies Press. Global Trends in Obesity. Current Status and Response to the Global Obesity Pandemic: Proceedings of a Workshop. National Academies of Sciences, Engineering, and Medicine; Health and Medicine Division; Food and Nutrition Board; Roundtable on Obesity Solutions; Callahan EA, editor. Washington (DC): National Academies Press (US); 2019 Jun 25.

2. World Health Organization. Obesity and overweight. Key facts. 2016. Available at: https://www.who.int/news-room/fact-sheets/detail/obesity-and-overweight.

3. Ng M, Fleming T, Robinson M, Thomson B, Graetz N, Margono C, et al. Global, regional, and national prevalence of overweight and obesity in children and adults during 1980-2013: a systematic analysis for the Global Burden of Disease Study 2013. Lancet. 2014 Aug 30;384(9945):766-81.

4. Chen $\mathrm{C}, \mathrm{Xu} \mathrm{X}$, Yan Y. Estimated global overweight and obesity burden in pregnant women based on panel data model. PloS one. 2018;13(8):e0202183.

5. AIHW. Australian Government. Australian Institute of Health and Welfare. Australia's mothers and babies. 2017. Available at: https://www.aihw.gov.au/getmedia/2a0c22a2-ba27-4ba0-ad47ebbe51854cd6/aihw-per-100-in-brief.pdf.aspx?inline=true.

6. Liu P, Xu L, Wang Y, Zhang Y, Du Y, Sun Y, et al. Association between perinatal outcomes and maternal pre-pregnancy body mass index. Obes Rev. 2016 Nov;17(11):1091-102.

7. Heslehurst N, Vieira R, Akhter Z, Bailey H, Slack E, Ngongalah L, et al. The association between maternal body mass index and child obesity: A systematic review and meta-analysis. PLoS Med. 2019 
Jun;16(6):e1002817.

8. Poston L, Harthoorn LF, Van Der Beek EM, Contributors to the IEW. Obesity in pregnancy: implications for the mother and lifelong health of the child. A consensus statement. Pediatr Res. 2011 Feb;69(2):175-80.

9. Campbell JM, McPherson NO. Influence of increased paternal BMI on pregnancy and child health outcomes independent of maternal effects: A systematic review and meta-analysis. Obes Res Clin Pract. 2019 Nov - Dec;13(6):511-21.

10. Oldereid NB, Wennerholm UB, Pinborg A, Loft A, Laivuori H, Petzold M, et al. The effect of paternal factors on perinatal and paediatric outcomes: a systematic review and meta-analysis. Hum Reprod Update. 2018 May 1;24(3):320-89.

11. McPherson NO, Fullston T, Aitken RJ, Lane M. Paternal obesity, interventions, and mechanistic pathways to impaired health in offspring. Annals of nutrition \& metabolism. 2014;64(3-4):231-8.

12. Adhikari P. Socio-Economic Indexes for Areas: Introduction, Use and Future Durections. Australian Bureau of Statistics. 2006;1351.0.55.015.

13. Dobbins TA, Sullivan EA, Roberts CL, Simpson JM. Australian national birthweight percentiles by sex and gestational age, 1998-2007. Med J Aust. 2012 Sep 3;197(5):291-4.

14. Thalluri V, Tremellen KP. Ultrasound diagnosed adenomyosis has a negative impact on successful implantation following GnRH antagonist IVF treatment. Hum Reprod. 2012 Dec;27(12):3487-92.

15. Abraham M, Alramadhan S, Iniguez C, Duijts L, Jaddoe VW, Den Dekker HT, et al. A systematic review of maternal smoking during pregnancy and fetal measurements with meta-analysis. PLoS One. 2017;12(2):e0170946.

16. Andriani H, Kuo HW. Adverse effects of parental smoking during pregnancy in urban and rural areas. BMC Pregnancy Childbirth. 2014 Dec 31;14:414.

17. Siega-Riz AM, Viswanathan M, Moos MK, Deierlein A, Mumford S, Knaack J, et al. A systematic review of outcomes of maternal weight gain according to the Institute of Medicine recommendations: birthweight, fetal growth, and postpartum weight retention. American journal of obstetrics and gynecology. 2009 Oct;201(4):339 e1-14.

18. Luke B, Stern JE, Kotelchuck M, Declercq ER, Cohen B, Diop H. Birth Outcomes by Infertility Diagnosis Analyses of the Massachusetts Outcomes Study of Assisted Reproductive Technologies (MOSART). J Reprod Med. 2015 Nov-Dec;60(11-12):480-90.

19. Ma M, Zhang W, Zhang J, Liang Z, Kuang Y, Wang Y. Effect of paternal body mass index on neonatal outcomes of singletons after frozen-thawed embryo transfer cycles: analysis of 7,908 singleton newborns. Fertil Steril. 2020 May 10.

20. McPherson NO, Bell VG, Zander-Fox DL, Fullston T, Wu LL, Robker RL, et al. When two obese parents are worse than one! Impacts on embryo and fetal development. Am J Physiol Endocrinol Metab. 2015 Sep 15;309(6):E568-81.

21. Ornellas F, Souza-Mello V, Mandarim-de-Lacerda CA, Aguila MB. Programming of obesity and comorbidities in the progeny: lessons from a model of diet-induced obese parents. PLoS One. 2015;10(4):e0124737.

22. Rath SR, Marsh JA, Newnham JP, Zhu K, Atkinson HC, Mountain J, et al. Parental pre-pregnancy BMI is a dominant early-life risk factor influencing BMI of offspring in adulthood. Obesity Science \& Practice. 2016 Mar;2(1):48-57.

23. Yu Z, Han S, Zhu J, Sun X, Ji C, Guo X. Pre-pregnancy body mass index in relation to infant birth weight and offspring overweight/obesity: a systematic review and meta-analysis. PLoS One. 2013;8(4):e61627. 
24. Gomez-Lopez L, Van Hulst A, Barnett TA, Roy-Gagnon MH, Tremblay A, O'Loughlin J, et al. Does parental body mass index status modify the associations among birth weight, early growth and childhood adiposity? Paediatr Child Health. 2013 Feb;18(2):e2-9.

25. Sorensen T, Ajslev TA, Angquist L, Morgen CS, Ciuchi IG, Davey Smith G. Comparison of associations of maternal peri-pregnancy and paternal anthropometrics with child anthropometrics from birth through age 7 y assessed in the Danish National Birth Cohort. Am J Clin Nutr. 2016 Aug;104(2):389-96.

26. Chen YP, Xiao XM, Li J, Reichetzeder C, Wang ZN, Hocher B. Paternal Body Mass Index (BMI) Is Associated with Offspring Intrauterine Growth in a Gender Dependent Manner. Plos One. 2012 May;7(5).

27. Noor N, Cardenas A, Rifas-Shiman SL, Pan H, Dreyfuss JM, Oken E, et al. Association of Periconception Paternal Body Mass Index With Persistent Changes in DNA Methylation of Offspring in Childhood. JAMA Netw Open. 2019 Dec 2;2(12):e1916777.

28. L'Abee C, Vrieze I, Kluck T, Erwich JJ, Stolk RP, Sauer PJ. Parental factors affecting the weights of the placenta and the offspring. J Perinat Med. 2011 Jan;39(1):27-34.

29. Pomeroy E, Wells JC, Cole TJ, O'Callaghan M, Stock JT. Relationships of maternal and paternal anthropometry with neonatal body size, proportions and adiposity in an Australian cohort. Am J Phys Anthropol. 2015 Apr;156(4):625-36.

30. Mutsaerts MA, Groen H, Buiter-Van der Meer A, Sijtsma A, Sauer PJ, Land JA, et al. Effects of paternal and maternal lifestyle factors on pregnancy complications and perinatal outcome. A populationbased birth-cohort study: the GECKO Drenthe cohort. Hum Reprod. 2014 Apr;29(4):824-34.

31. McCowan LME, North RA, Kho EM, Black MA, Chan EH, Dekker GA, et al. Paternal contribution to small for gestational age babies: A multicenter prospective study. Obesity. 2011;19(5):1035-9.

32. Yang S, Zhou A, Xiong C, Yang R, Bassig BA, Hu R, et al. Parental Body Mass Index, Gestational Weight Gain, and Risk of Macrosomia: A Population-Based Case-Control Study in China. Paediatric and perinatal epidemiology. 2015;29(5):462-71.

33. McPherson NO, Lane M, Sandeman L, Owens JA, Fullston T. An Exercise-Only Intervention in Obese Fathers Restores Glucose and Insulin Regulation in Conjunction with the Rescue of Pancreatic Islet Cell Morphology and MicroRNA Expression in Male Offspring. Nutrients. 2017 Feb 09;9(2).

34. McPherson NO, Owens JA, Fullston T, Lane M. Preconception diet or exercise interventions in obese fathers normalizes sperm microRNA profile and metabolic syndrome in female offspring. Am J Physiol Endocrinol Metab. 2015 Feb 17:E pub 17/02/15.

35. Fullston T, Teague EM, Palmer NO, de Blasio MJ, Mitchell M, Print CG, et al. Paternal obesity initiates metabolic disturbances in two generations of mice and alters the transcription profile of tesis and sperm microRNA content. FASEB J. 2013;27(10):4226-43.

36. Bromfield JJ. Seminal fluid and reproduction: much more than previously thought. J Assist Reprod Genet. 2014 Jun;31(6):627-36.

37. Donkin I, Barres R. Sperm epigenetics and influence of environmental factors. Mol Metab. 2018 Aug;14:1-11.

38. Herrera BM, Keildson S, Lindgren CM. Genetics and epigenetics of obesity. Maturitas. 2011 May;69(1):41-9.

39. Warrington NM, Howe LD, Wu YY, Timpson NJ, Tilling K, Pennell CE, et al. Association of a body mass index genetic risk score with growth throughout childhood and adolescence. PLoS One. 2013;8(11):e79547.

40. Chen Q, Yan M, Cao Z, Li X, Zhang Y, Shi J, et al. Sperm tsRNAs contribute to intergenerational inheritance of an acquired metabolic disorder. Science. 2016 Jan 22;351(6271):397-400. 
41. Lambrot R, Xu C, Saint-Phar S, Chountalos G, Cohen T, Paquet M, et al. Low paternal dietary folate alters the mouse sperm epigenome and is associated with negative pregnancy outcomes. Nature communications. 2013;4:2889.

42. Terashima M, Barbour S, Ren J, Yu W, Han Y, Muegge K. Effect of high fat diet on paternal sperm histone distribution and male offspring liver gene expression. Epigenetics. 2015 Sep 2;10(9):861-71.

43. Ost A, Lempradl A, Casas E, Weigert M, Tiko T, Deniz M, et al. Paternal diet defines offspring chromatin state and intergenerational obesity. Cell. 2014 Dec 4;159(6):1352-64.

44. Soubry A, Schildkraut JM, Murtha A, Wang F, Huang Z, Bernal A, et al. Paternal obesity is associated with IGF2 hypomethylation in newborns: results from a Newborn Epigenetics Study (NEST) cohort. BMC medicine. 2013;11:29.

45. Cunningham SA, Kramer MR, Narayan KM. Incidence of childhood obesity in the United States. N Engl J Med. 2014 Jan 30;370(5):403-11.

46. O’Brien AP, Hurley J, Linsley P, McNeil KA, Fletcher R, Aitken JR. Men's Preconception Health: A Primary Health-Care Viewpoint. Am J Mens Health. 2018 Sep;12(5):1575-81.

\section{FIGURE LEGENDS}

\section{Figure 1: Joint association of parental BMI on infant birthweight.}

The effect of the interaction is illustrated by varying maternal (A \& B ) and paternal BMI (C \& D ) with the other parental BMI set at 20 and $35 \mathrm{~kg} / \mathrm{m}^{2}$ respectively. Grey circles are observed birth weights. Solid red lines are the median model estimates, dashed lines are $10^{\text {th }}$ and $90^{\text {th }}$ percentiles and dotted lines are the $5^{\text {th }}$ and $95^{\text {th }}$ percentile models. 95\% confidence intervals (blue bars) are presented for parental BMIs of 20 $\mathrm{kg} / \mathrm{m}^{2}, 27.5 \mathrm{~kg} / \mathrm{m}^{2}$ and $35 \mathrm{~kg} / \mathrm{m}^{2}$. These estimates are for IVF insemination, vaginal births and female babies and have other continuous covariates set at their median values.

Figure S1: Cohort inclusion flow-diagram.

Figure S2: Comparison of baby weights with population estimates reported in Dobbins et al. 2007.

A Female birthweight and $\mathbf{B}$ male birthweight. Solid black lines represent population median estimates, dashed lines are $10^{\text {th }}$ and $90^{\text {th }}$ percentiles and dotted lines are the $1^{\text {st }}$ and $99^{\text {th }}$ percentile.

Figure S3: Associations of risk factors on infant birthweight.

A Gestational age, B SEFIA score, $\mathbf{C}$ maternal age and D paternal age. Grey circles are observed birth weights. Solid red lines are the median model estimates, dashed lines are $10^{\text {th }}$ and $90^{\text {th }}$ percentiles and dotted lines are the $5^{\text {th }}$ and $95^{\text {th }}$ percentile models. These estimates are for IVF insemination, vaginal births and female babies and have continuous covariates set at their median values.

Table 1 : Summary of parental demographics, treatment choices and birth outcomes.

\begin{tabular}{|c|c|c|c|}
\hline 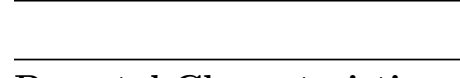 & & & $\mathrm{N}=1479$ \\
\hline \multirow[t]{9}{*}{ Parental Characteristics } & \multirow{4}{*}{$\begin{array}{l}\text { Parental Characteristics } \\
\text { Maternal age (years) }\end{array}$} & Parental Characteristics & \\
\hline & & Maternal age (years) & \\
\hline & & Median (range) & $32.9(19.9,45.2)$ \\
\hline & & Mean (SD) & $32.83(4.17)$ \\
\hline & \multirow[t]{3}{*}{ Paternal age (years) } & Paternal age (years) & \\
\hline & & Median (range) & $35.2(21.3,62.8)$ \\
\hline & & Mean (SD) & $36.15(6.27)$ \\
\hline & \multirow{2}{*}{ Maternal BMI $\left(\mathrm{kg} / \mathrm{m}^{2}\right)$} & Maternal BMI $\left(\mathrm{kg} / \mathrm{m}^{2}\right)$ & \\
\hline & & Median (range) & $24.4(16.2,55.9)$ \\
\hline
\end{tabular}




\begin{tabular}{|c|c|c|c|}
\hline & & & $\mathrm{N}=1479$ \\
\hline & & Mean (SD) & $25.9(5.96)$ \\
\hline & & Missing & $6(<1 \%)$ \\
\hline & Paternal BMI $\left(\mathrm{kg} / \mathrm{m}^{2}\right)$ & Paternal BMI $\left(\mathrm{kg} / \mathrm{m}^{2}\right)$ & \\
\hline & & Median (range) & $27.4(17.3,54.2)$ \\
\hline & & Mean $(\mathrm{SD})$ & $28.11(4.65)$ \\
\hline & & Missing & $278(19 \%)$ \\
\hline & SEFIA & SEFIA & \\
\hline & & Median (range) & $1000(673,1151)$ \\
\hline & & Mean $(\mathrm{SD})$ & $995(69)$ \\
\hline & & Missing & $22(1 \%)$ \\
\hline \multirow[t]{6}{*}{ Infertility Diagnosis } & Infertility Diagnosis & Infertility Diagnosis & \\
\hline & Tubal factor & Tubal factor & $112(8 \%)$ \\
\hline & Endometrial factor & Endometrial factor & $101(7 \%)$ \\
\hline & Male factor & Male factor & $818(55 \%)$ \\
\hline & Other & Other & $536(36 \%)$ \\
\hline & Unexplained & Unexplained & $282(19 \%)$ \\
\hline \multirow[t]{17}{*}{ Birth Factors } & Birth Factors & Birth Factors & \\
\hline & Insemination method & Insemination method & \\
\hline & & IVF & $232(16 \%)$ \\
\hline & & ICSI & $1247(84 \%)$ \\
\hline & Delivery method & Delivery method & \\
\hline & & Vaginal & $871(59 \%)$ \\
\hline & & Caesarean & $607(41 \%)$ \\
\hline & & Missing & $1(<1 \%)$ \\
\hline & Gestational length (weeks) & Gestational length (weeks) & \\
\hline & & Median (range) & $39.14(37,42.14)$ \\
\hline & & Mean $(\mathrm{SD})$ & $39.13(1.08)$ \\
\hline & Infant Sex & Infant Sex & \\
\hline & & Female & $745(50 \%)$ \\
\hline & & Male & $734(50 \%)$ \\
\hline & Infant birthweight (g) & Infant birthweight $(\mathrm{g})$ & \\
\hline & & Median (range) & $3345(1587,4998)$ \\
\hline & & Mean (SD) & $3367.66(453.1)$ \\
\hline
\end{tabular}

$\mathrm{BMI}=$ body mass index; SEIFA = socioeconomic index for areas; $\mathrm{SD}=$ standard deviation; IVF $=$ In vitro fertilisation; ICSI = intracytoplasmic sperm injection;

Table 2: Quantile regression fits for infants small for gestation age (SGA).

\begin{tabular}{llllll}
\hline & 5 th Percentile & 5th Percentile & 10th Percentile & 10th Percentile & M \\
\hline Birth Factors & Est $[95 \%$ CI $]$ & p-value & Est $[95 \%$ CI $]$ & p-value & Es \\
Sex (male v female) & $112[46.5,178]$ & $\mathbf{0 . 0 0 0 8}$ & $63.3[7.28,119]$ & $\mathbf{0 . 0 3}$ & 10 \\
Gestational age & $275[193,358]$ & $<\mathbf{0 . 0 0 0 1}$ & $212[129,294]$ & $<\mathbf{0 . 0 0 0 1}$ & 20 \\
Gestational age (non-linear) & & $\mathbf{0 . 0 0 4}$ & $-30[-103,42.6]$ & 0.42 & -8 \\
Insemination method (ICSI v IVF) & $-3.36[-90.4,83.7]$ & 0.94 & $7.09[-54.5,68.7]$ & 0.82 & 80 \\
$\begin{array}{l}\text { Delivery (caesarean vs vaginal) } \\
\text { Parental Factors }\end{array}$ & $-13[-82.5,56.5]$ & 0.71 & $-15.2[-23,-7.34]$ & $\mathbf{0 . 0 0 0 1}$ & -7 \\
Maternal age & $-12.3[-21.4,-3.17]$ & $\mathbf{0 . 0 0 8}$ & & &
\end{tabular}




\begin{tabular}{llllll}
\hline & 5 th Percentile & 5 th Percentile & 10 th Percentile & 10th Percentile & M \\
\hline Paternal age & $6.97[2.05,11.9]$ & $\mathbf{0 . 0 0 6}$ & $9.5[4.15,14.8]$ & $\mathbf{0 . 0 0 0 5}$ & 2. \\
SEIFA & $32.9[-4.36,70.1]$ & $\mathbf{0 . 0 8}$ & $32[7.92,56.1]$ & $\mathbf{0 . 0 0 9}$ & $\mathbf{0 . 0 0 1}$ \\
Maternal BMI & $37.4[18.3,56.6]$ & $\mathbf{0 . 0 0 0 1}$ & $29.9[11.9,47.8]$ & $\mathbf{0 . 0 1}$ & 15 \\
Maternal BMI (non-linear) & & $\mathbf{0 . 0 0 2}$ & & $\mathbf{0 . 0 3}$ & \\
Paternal BMI & $3.07[-8.26,14.4]$ & 0.60 & $2.43[-4.91,9.78]$ & 0.52 & 7. \\
Interaction: Maternal BMI x Paternal BMI & $0.0621[-1.25,1.38]$ & 0.93 & $-0.241[-1.3,0.82]$ & 0.66 & -0 \\
\hline
\end{tabular}

$\mathrm{BMI}=$ Body mass index; ICSI $=$ intracytoplasmic sperm injection; IVF $=$ In vitro fertilisation; SEIFA $=$ socioeconomic index for areas.

Table 3: Quantile regression fits for infants large for gestation age (LGA).

\begin{tabular}{llllll}
\hline & Median & Median & 90 th Percentile & 90 th Percentile & 95 \\
\hline & Est $[95 \% \mathrm{CI}]$ & p-value & Est $[95 \% \mathrm{CI}]$ & p-value & Es \\
Birth Factors & & & & & \\
Sex (male v female) & $106[55.9,157]$ & $\mathbf{0 . 0 0 0 1}$ & $142[77.5,207]$ & $<\mathbf{0 . 0 0 0 1}$ & 13 \\
Gestational age & $209[160,258]$ & $\mathbf{0 . 0 0 0 1}$ & $175[112,237]$ & $<\mathbf{0 . 0 0 0 1}$ & 21 \\
Gestational age (non-linear) & & $\mathbf{0 . 0 0 2}$ & - & 0.16 & \\
Insemination method (ICSI v IVF) & $-8.87[-73.1,55.4]$ & 0.79 & $-33.2[-116,49.2]$ & 0.43 & -98 \\
Delivery (caesarean vs vaginal) & $80.4[26,135]$ & $\mathbf{0 . 0 0 4}$ & $133[62.3,203]$ & $\mathbf{0 . 0 0 0 2}$ & 15 \\
Parental Factors & & & & \\
Maternal age & $-7.47[-14.9,-0.0572]$ & $\mathbf{0 . 0 5}$ & $2.57[-6.8,11.9]$ & 0.59 & 3.5 \\
Paternal age & $2.86[-1.97,7.69]$ & 0.25 & $0.0827[-6.4,6.57]$ & 0.98 & 0.3 \\
SEIFA & $44.3[16.7,71.8]$ & $\mathbf{0 . 0 0 2}$ & $20.4[-14,54.9]$ & 0.25 & 28 \\
Maternal BMI & $15.9[1.63,30.1]$ & $\mathbf{0 . 0 3}$ & $9.48[-7.99,26.9]$ & 0.29 & 25 \\
Maternal BMI (non-linear) & & 0.61 & & 0.32 & \\
Paternal BMI & $7.33[0.297,14.4]$ & $\mathbf{0 . 0 4}$ & $3.28[-6.15,12.7]$ & 0.50 & \\
Interaction: Maternal BMI x Paternal BMI & $-0.977[-1.9,-0.0537]$ & $\mathbf{0 . 0 4}$ & $-0.577[-1.87,0.719]$ & 0.38 & -0.5 \\
\hline
\end{tabular}

$\mathrm{BMI}=$ Body mass index; ICSI = intracytoplasmic sperm injection; IVF $=$ In vitro fertilisation; SEIFA = socioeconomic index for areas.
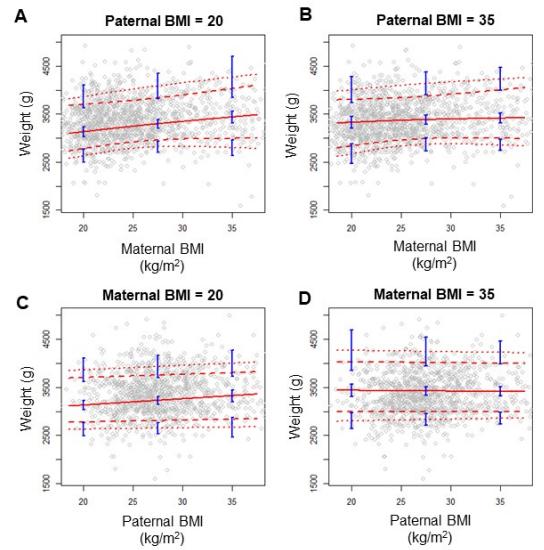